\title{
Educação superior a distância no Brasil: uma construção consorciada e em rede.
}

\author{
Luiz Roberto Rodrigues Martins*
}

Resumo Este artigo descreve a experiência de implantação da política de fomento aos cursos de Graduação a Distância (EAD) no Brasil adotada pela Secretaria de Educação a Distância do Ministério da Educação (SEED/MEC) a partir de 2004. Essa política prioriza a criação de cursos de licenciatura e a distância. Analisaremos essa experiência pioneira e ainda não consolidada, buscando interpretar os fatores que dificultam a institucionalização da EAD no ensino superior. Nesse trabalho analisaremos algumas alternativas de institucionalização apresentadas pelos oito consórcios participantes da Chamada Pública 001/2004 SEED/MEC na reunião de trabalho realizada em abril de 2005. As proposições dos consórcios, encaminhadas ao MEC pela UniRede, pretendem assegurar a continuidade da política pública de fomento à EAD no ensino superior público, garantindo a continuidade dos cursos oferecidos e a ampliação de vagas nos próximos anos.

Palavras-chave políticas públicas, educação a distância, institucionalização da EAD

\begin{abstract}
This article describes the implementation of the first phase of the Program for Distance Education focused on Graduation Courses offered by the Ministry of Education through its Secretariat for Distance Education (SEED/MEC) in 2004. This public policy priorizes the course for teachers in different fields of knowledge. This newly proposed policy is not yet institutionalied in Higher Education. This article discusses alternatives for the eventual institutionalization of Distance Learning Programs through a cooperative scheme among eight consortions that participated in the Public Calling sponsered by the Ministry of Education and in a workshop for participants in april 2005. The propositions intend to assure the continuity of the public policies of incentives and support for Distance Education Programs.
\end{abstract}

Keywords public policies, distance education, distance education institutionalization

\section{Introdução}

A crise da Universidade tem sido objeto de diversos estudos e amplos debates que buscam novos cenários e soluções alternativas em todos os continentes. Segundo a Conferência Mundial sobre Ensino Superior da UNESCO, realizada em Paris em outubro de 1998, no capítulo que se refere

\footnotetext{
* Luiz Roberto Rodrigues Martins é Mestrando em Educação pela Universidade de Brasília, atua na Secretaria de Educação a Distância do Ministério da Educação.
} 
à Educação Aberta e a Distância, ${ }^{1}$ as limitações do acesso à educação, tanto para jovens como para adultos, podem ter sua solução na adoção das Tecnologias de Informaçãa e Comunicação (TIC): uma saída para a democratização do acesso ao ensino superior. Embora reconheça que em países em desenvolvimento a Educação a Distância (EAD) enfrente os mesmos problemas da educação convencional, acrescida das carências de infra-estrutura existentes no país, o artigo propõe que a política de planejamento educacional inclua a EAD de forma visível e forte, devendo receber apoio do alto escalão governamental.

No contexto das Instituições Públicas de Ensino Superior (IPES) brasileiras a educação aberta e a distância têm enfrentado dificuldades para sua institucionalização. $O$ empenho nas questões relacionadas com a oferta de ensino presencial relega a EAD para um segundo plano no rol das prioridades atuais das IPES do país. Questões relativas ao financiamento do ensino superior público, dificuldades de contratação de professores, ausência de infra-estrutura tecnológica e outros pontos que envolvem a complexidade da oferta de ensino mediatizado por material impresso, material multimídia, canais de TV e rádio retardam a adoção da EAD como forma de ensino-aprendizagem com potencial de oferta em grande escala no ensino superior brasileiro. Porém, não se trata apenas de oferta industrial de ensino, mas de ensino de qualidade, com possibilidades de troca interativa de idéias, conceitos, saberes e conhecimentos entre professorestutores e cursistas e entre os próprios cursistas.

Na proposta ANDES-SN ${ }^{2}$, publicada em outubro de 2003, no que se refere à "expansão da rede pública de ensino em todos os níveis e modalidades", há uma preocupação explícita com o aproveitamento da "capacidade física instalada para ensino pesquisa e extensão". Contudo, o texto prevê como estratégia especial para expansão, a oferta de ensino noturno (item 4.1.4). Se comparada com o potencial de alcance da EAD para a ampliação da oferta de ensino superior de qualidade no país, essa opção parece bastante tímida. No mesmo artigo, quando trata do papel da universidade como "representação social, cultural, intelectual e científica", afirma-se que a "...condição básica para assegurar essa representatividade é a capacidade de assegurar uma produção de conhecimento inovador e crítico que respeite a diversidade e o pluralismo e não simplesmente preencha uma função de reprodução de estruturas, relações e valores...". A aceitação da EAD pelas universidades poderá trazer maior representatividade para as IPES, no que se refere ao acesso ao ensino superior cuja participação social ficou reduzida nas últimas duas décadas (somente cerca de $20 \%$ dos alunos do ensino superior são atendidos pela rede pública, os $80 \%$ restantes pelas instituições privadas).

Essa situação politicamente incômoda poderá ser minorada com a adoção da EAD como instrumento para a expansão da oferta de vagas no ensino superior. Apesar de aparentemente favoráveis e de reconhecerem o valor da EAD, dirigentes das IPES pouco fazem para o fomento dessa modalidade de ensino em suas instituições. Tentando aproximar educação presencial de educação a distância nos lembra Moran,

O objetivo dos cursos presenciais e virtuais é o mesmo que os alunos aprendam. Podem mudar algumas formas de ensinar, de organizar a aprendizagem, as mídias, mas no conjunto os processos são semelhantes. Discute-se bastante a autonomia e identidade pedagógicas dos cursos a distância. Com a comunicação on-line, a pedagogia do presencial se modifica e a da educação a distância também. Há uma convergência de

\footnotetext{
1 Organização das Nações Unidas para a Educação, a Ciência e a Cultura (1999).

${ }^{2}$ Proposta do Andes-SN para a universidade brasileira (1981).
} 
métodos e técnicas de ensino-aprendizagem, com diferentes ênfases (MORAN, 2003).

$\mathrm{Na}$ última década, algumas IPES pioneiras trabalharam de forma pontual e isolada na oferta de cursos de licenciatura a distância. Buscando formar 10.000 professores em 10 anos, a despeito das restrições existentes, a Universidade Federal de Mato Grosso, pioneira em ofertar cursos de licenciatura por meio da EAD no país, desenvolveu sua proposta de trabalho "com base nas discussões e nas definições de uma Política de Ensino e Pesquisa do Instituto de Educação no momento de sua criação em 1992". Articulada entre o Sindicato dos Trabalhadores de Educação, o Sistema Público de Ensino do Estado e as Universidades (Federal e Estadual) e visando a formação do educador das séries iniciais, da 5 a a 8a. séries e a oferta de cursos de pós graduação, a experiência em Mato Grosso se desenvolveu apoiada em uma proposta de ensino-pesquisa e teoria prática. (ALONSO, 2000). A partir da experiência realizada em Mato Grosso, outras universidades iniciaram seus processos de credenciamento e autorização de cursos de graduação a distância. Algumas delas já haviam iniciado a criação de seus Centros de Educação a Distância para oferta de cursos de especialização e de extensão, experiências que muitas vezes estavam restritas à ousadia de um pequeno número de professores que se interessavam pelo tema e realizavam esses cursos mediante convênios por prazo determinado.

Após a adoção da EAD, restrita à iniciativa específica de cada unidade universitária, começam a surgir consórcios entre universidades, assim como propostas de parcerias entre universidades e governos estaduais e municipais para viabilizar cursos a distância com apoio interinstitucional.

A criação, em 2000, de grandes consórcios nacionais de universidades públicas federais (UniRede $^{3}$, do CEDERJ ${ }^{4}$ - consórcio de universidades do Rio de Janeiro - e do Projeto Veredas ${ }^{5}$ em Minas Gerais) é um exemplo bem sucedido de colaboração interinstitucional, importante para a EAD no país. Essas iniciativas de oferta consorciada de EAD serviram de inspiração para o estabelecimento da política de fomento à EAD, desenvolvida pelo Ministério da Educação a partir do segundo semestre de 2004. Uma experiência que embora esteja ainda no início, mostrase promissora no sentido de transformar definitivamente a situação institucional da EAD no espaço das IPES Brasileiras.

O Edital 001/2004 publicado em julho de 2004 pela Secretaria de Educação a Distância do Ministério da Educação (SEED/MEC), mobilizou as instituições públicas de ensino superior para oferta de cursos de licenciatura a distância em Pedagogia, Física, Química, Biologia e

\footnotetext{
${ }^{3}$ O Termo de Adesão assinado por representantes de 62 instituições de ensino superior, em 23 de agosto de 2000, cria a UniRede (www.unirede.br) e dispõe seus objetivos e condições gerais de funcionamento. Outras sete instituições assinaram o termo posteriormente, perfazendo o total de 69 consorciados.Pelo documento, em vigência até agosto de 2005, os signatários comprometem-se a compartilhar recursos humanos, tecnológicos e infra-estrutura para aprimorar o ensino nas áreas de Educação, Ciência, Tecnologia, Arte e Cultura, tornando-o disponível por meios interativos. Para isso, devem celebrar convênios com o objetivo de fazer o intercâmbio de experiências, metodologias e materiais didáticos

${ }^{4}$ A Fundação Cecierj/Consórcio Cederj, criada em 1 de abril de 2002, com a união da autarquia Centro de Ciências do Estado do Rio de Janeiro (Cecierj) e o Centro de Educação a Distância do Estado do Rio de Janeiro (Cederj) pelo governador do Estado do Rio de Janeiro, Anthony Garotinho.

${ }^{5}$ A Secretaria de Estado da Educação de Minas Gerais implementou curso de Formação Superior de Professores dos anos iniciais do Ensino Fundamental, que teve início em janeiro de 2002. Esse projeto recebeu a denominação de Veredas - Formação Superior de Professores (www.veredas. educacao. mg.gov.br), voltando-se para uma das prioridades do Governo Estadual, que é garantir escola pública de boa qualidade para todos, como forma de contribuir para a construção de uma sociedade mais justa, democrática e solidária.Trata-se de um Curso Normal Superior ministrado na modalidade de educação a distância para 14.700 professores das redes estadual e municipais que estejam, em efetivo exercício nos anos iniciais do Ensino Fundamental.
} 
Matemática. A escolha prioritária dessas áreas de conhecimento foi baseada em dados do Censo do Professor (INEP) que revelavam um déficit crescente de professores no ensino médio de Matemática e de Ciências da Natureza, e a falta de formação superior entre os docentes do ensino fundamental, principalmente nas séries iniciais. O Edital disponibilizou $\mathrm{R} \$ 14.000 .000,00$ (catorze milhões de reais) para preparação e ampliação de vagas para Cursos de Licenciatura a Distância em todas as áreas citadas. Foram selecionados 8(oito) consórcios de universidades públicas que envolveram 39 instituições, oferecendo 19 diferentes cursos em todas as regiões do país, com o propósito de cobrir 17.585 novas vagas. Os critérios para seleção das propostas de cursos privilegiavam cinco pontos fundamentais: Abrangência Geopolítica, Oferta de Vagas, Equipe Multidisciplinar, Projeto Pedagógico e Estrutura Administrativa. O Projeto Pedagógico recebeu peso 5, a Estrutura Administrativa peso 3 e os outros fatores peso 4.

Uma comissão multidisciplinar de especialistas em Educação a Distância, Pedagogia, Física, Química, Biologia e Matemática selecionou as melhores propostas, ajustando a alocação dos recursos com base na pontuação obtida por cada projeto de curso de acordo com os critérios estabelecidos no Edital. (Anexo I - Consórcios vencedores)

O trabalho de implementação da primeira fase dos convênios - elaboração de materiais didáticos para os cursos - foi iniciado ainda em 2004 com o apoio da equipe técnica da SEED/MEC que instituiu, junto às universidades conveniadas, um sistema de acompanhamento da execução orçamentária, financeira e pedagógica dos convênios firmados. Esse trabalho de parceria exigiu do Ministério da Educação e das universidades um novo tipo de relacionamento baseado na confiança mútua e na disposição para buscar resultados, gerando uma construção cooperativa inédita de relacionamento entre IPES e o Governo Federal. A visita de técnicos do MEC às Universidades garantiu o acompanhamento in loco das ações contidas nos Planos de Trabalho aprovados, não de forma meramente burocrática mas com uma visão gerencial que antecipava problemas e buscava soluções conjuntas para os problemas porventura identificados. Antes disso, o relacionamento entre o MEC e as instituições conveniadas se limitava ao cumprimento das exigências legais que prevêem a prestação de contas a posteriori, ou seja, após o término do Convênio no caso de repasse em parcela única. Esse tipo de acompanhamento ao final torna-se burocrático, pois visa a cumprir regras de auditoria e não assegura o bom andamento dos trabalhos sob o ponto de vista da garantia dos fatores de sucesso para esse tipo de empreendimento.

A integração entre as equipes técnicas favorece a correção de rumos, por meio do diálogo objetivo e da conciliação de interesses entre as Universidades e o Governo Federal, dando um novo sentido às parcerias estabelecidas. Pela primeira vez a atuação conjunta tem demonstrado uma capacidade de articulação importante para a solução objetiva dos problemas de construção de Cursos a Distância em rede nessas universidades. As sugestões da UniRede, da Andifes e de outras organizações representativas da educação superior têm sido consideradas na formulação e na estruturação dessa política de forma consistente e conseqüente. É uma política construída de forma aberta e participativa.

Uma mudança introduzida por essa política se refere à construção de uma organização em rede que extrapola cada universidade isoladamente e faz com que recursos humanos, materiais e tecnológicos sejam compartilhados entres os membros dos consórcios. Embora a figura jurídica do consórcio se reduza a um acordo firmado entre os reitores de cada instituição, está evidente que a construção dessas parcerias não se faz de forma burocrática. A construção do conceito de ação consorciada ou em parceria nasceu com as experiências das universidades na UniRede, o que facilitou a execução dos projetos em consórcio.

São relacionamentos construídos com base no interesse comum da oferta dos cursos. Isso significa, ter que administrar conflitos, discutir soluções heterogêneas, alocar recursos para uso 
comum e praticar paciência, boa vontade e generosidade o tempo todo. Não é fácil reunir grupos distintos de especialistas, com seus vieses já estabelecidos, trabalhando em instituições diferentes, de modo a produzir resultados de forma integrada. Apesar do pouco tempo de implementação da primeira fase, há indicações de que a implementação dos cursos se fará sem rupturas por parte das instituições envolvidas.

A implantação desse política se confirma nos acertos e prazos firmados entre a equipe do MEC e a coordenação das equipes produtoras de material didático nas Universidades. As visitas de técnicos do MEC, para prevenção de possíveis problemas administrativos, orçamentários e pedagógicos, serviram para estabelecer formas de comunicação pró-ativa, até então inexistentes, entre a SEED/MEC e as Universidades. A filosofia de trabalho adotada respeita a autonomia universitária, cabendo às equipes do MEC o papel de articuladores de soluções na mediação de impasses e conflitos ao invés de meros fiscais burocráticos, função comumente esperada nesse tipo de convênio. O objetivo principal da parceria é assegurar maior número de vagas no ensino superior público, o que avança de forma acelerada, apesar das incertezas existentes.

A equipe MEC se mantém próxima das instituições, não para puni-las ou fiscalizá-las, mas para agilizar processos burocráticos e apoiá-las institucionalmente atendendo suas demandas mais urgentes. Desde o primeiro momento, foram realizadas reuniões com as equipes das universidades e visitas de acompanhamento técnico. Essa atitude de cooperação e apoio mútuo estimulou as universidades a se empenharem na elaboração dos materiais dentro dos prazos propostos.

Entretanto, em alguns casos, os conflitos internos gerados pelas trocas de reitores (dois casos) ou por desentendimentos interinstitucionais (dois casos) fez com que as equipes iniciais se desestabilizassem e alguns dos cronogramas sofressem atrasos, mas devido a participação próativa da SEED na identificação dos problemas, soluções imediatas foram acordadas para a retomada das metas estabelecidas. Outro fator positivo para a solução de conflitos e dificuldades foi a reunião promovida pela SEED com a participação de todas as instituições envolvidas. Nessa oportunidade muitas dificuldades foram vencidas com a colaboração de todos os membros do consórcio.

Contudo, de um modo geral as IPES consorciadas têm demonstrado alto grau de motivação, interesse e cooperação. A oportunidade de implementação dos cursos de EAD, financiados especificamente por esses projetos, tem servido para demonstrar a viabilidade dessa modalidade de ensino de modo surpreendente, pois em pouco mais de 8 (oito) meses tem-se a perspectiva de oferta de 17.585 vagas no ensino superior público brasileiro, fato que equivale à criação de mais uma universidade pública de porte médio no cenário nacional em tempo recorde, ainda que aproveitando a infra-estrutura existente e parte dos professores altamente qualificados disponíveis nas universidades públicas.

Para promover a troca de experiências entre os coordenadores pedagógicos dos cursos em andamento, foram realizadas, em Brasília, nos dias 26,27 e 28 de abril de 2005, reuniões técnicas com representantes das 39 instituições participantes dos consórcios. Na primeira reunião, realizada com a participação da Secretaria de Educação a Distância, da Secretaria de Educação Especial, da Secretaria de Ensino Superior e da Secretaria de Educação Básica foi apresentado o Pró-Licenciatura - um programa do MEC lançado pela Secretaria de Ensino Básico junto com a Secretaria de Educação a Distância, que visa ofertar, além das licenciaturas já indicadas, licenciaturas para professores em exercício das matrizes curriculares do ensino fundamental e médio. Nas reuniões seguintes foram discutidos temas relevantes para a institucionalização definitiva da EAD nas IPES nacionais. Iniciamos com a discussão da implementação dos pólos ou centros de estudo nos espaços geográficos de cada projeto, aspectos relevantes concernentes à tutoria e às metodologias pedagógicas, pontos críticos para a gestão e formas de avaliação em 
todos o níveis. Operando com trabalhos de grupos e reuniões plenárias destacamos alguns tópicos que serviram para sintetizar os pontos mais relevantes das discussões realizadas. Esses pontos serviram de base para a construção de um documento (ver anexo II) que ao final da reunião foi enviado formalmente ao MEC pela UNIREDE como contribuição às medidas que servirão para consolidar a EAD no país.

A seguir analisaremos de forma sintética alguns dos pontos levantados por esse documento:

a) Abertura de novas vagas para docentes e técnicos administrativos, que atendam a demanda dos programas de educação a distância.

Essa tem sido uma real dificuldade das universidades. Com quadros de pessoal comprimidos na última década. (Os professores das instituições públicas de ensino superior federal, estadual e municipal eram 71.904 em todo o país em 1990 e, em 2000 eram 88.154. Os servidores nas universidades federais eram 100.517 em 1995 e 69.411 em 2000 -INEP-).

O resultado dessa situação são universidades públicas operando com quadros de professores e funcionários desfalcados. Os professores encontram-se sobrecarregados pelas tarefas de ensino, pesquisa e extensão e o quadro de funcionários situa-se abaixo das necessidades.

Para ampliar as vagas nas universidades, mantendo-se a qualidade de ensino-pesquisa-extensão, faz-se necessária a ampliação do número de professores e servidores, de preferência com profissionais que tenham um perfil que possa englobar o uso das TIC na sua prática de ensinopesquisa-extensão.

Essas questões passam pelo crivo do financiamento das universidades e pelo investimento federal no ensino superior público.

Para atender a uma determina demanda por vagas os cursos a distância requerem um menor número de professores que os cursos presenciais. Experiências internacionais como a Open University e a Universidade Nacional de Educação a Distância na Espanha revelam que os professores ocupam um papel indispensável, porém diferenciado, no ensino de qualidade em larga escala.

b) Viabilização institucional da remuneração de profissionais envolvidos no sistema de EAD

Com o advento da EAD a Universidade deixa de ser uma organização concentrada em sua sede e campi avançados para prover uma maior capilaridade, gerando uma proximidade com as comunidades do interior do país. Contudo, isso implica na construção, adequação e ampliação de Centros de Estudos com recursos de telecomunicações, bibliotecas, computadores e salas de estudo. A idéia do projeto é ampliar o alcance da universidade mediante apoio de prefeituras e governos estaduais. Uma sala equipada para receber os cursistas de uma micro-região serve de base para a instalação da universidade nos sertões e interiores do país.

Essa estrutura e mais leve e mais econômica que a construção de universidades convencionais, onde toda a estrutura de ensino-pesquisa-extensão custaria muito mais que a disponibilização de salas equipadas para serem usadas como apoio em momentos presenciais.

O quadro de profissionais que atuam nas universidades pode ser dividido em funções docentes e funções de apoio administrativo. A realização de cursos a distância implica na contratação de coordenadores locais para a realização dos cursos e administração dos pólos, administração de tarefas, encaminhamento de requisições e outras atividades de secretaria dos cursos. Essas 
funções podem ser preenchidas também com apoio de parcerias com Secretarias Estaduais ou Prefeituras, dentre outras.

No que se refere às funções docentes há de se ampliar o quadro de professores para a realização de cursos com qualidade, apesar da rigidez legal hoje existente.

c) Inclusão dos alunos da Educação a Distância nas matrizes orçamentárias das IES públicas, para assegurar o custeio do sistema de EAD

$\mathrm{Na}$ alocação de recursos do Tesouro, até o final da década de 90, segundo Schwartzman (1991), o administrador universitário recebia mais incentivos para facilitar promoções, relaxar defesas trabalhistas, e contratar o maior número possível de pessoal administrativo inflando a folha de pagamento e com isso gerando mais ineficiência. A Matriz de alocação de OCC (Outros Custeios e Capital) criada a partir de então passa a considerar variáveis de pesquisa com peso de $15 \%$ e ensino com peso de $85 \%$ que engloba o turno do aluno, o número de alunos diplomados, a área de conhecimento dos Cursos, o volume e a avaliação qualitativa da pós- graduação. (S... pag. 190). Segundo esse mesmo autor, as IFES perderam a capacidade de gerar mais recursos para OCC, portanto a consideração do aluno de EAD na Matriz de repasse de recursos pode ser um estímulo à institucionalização dessa modalidade de ensino.Se considerarmos que um aluno de EAD (Curso de Licenciatura) oferece um custo médio de $\mathrm{R} \$ 1.500,00$ reais ano comparado com o custo ano de um aluno presencial que em 1998 estava em R $\$ 9.789,00$ (pag.198) ano, o aluno de EAD pode ser uma alternativa atraente para a expansão do ensino superior público no país. A inclusão do aluno de EAD na matriz passa por uma negociação com a Casa Civil e Ministério do Planejamento juntamente com o Ministério da Educação.

d) Destinação de recursos financeiros para implantar e implementar a infra-estrutura do sistema de EAD

Os sistemas de EAD funcionam de forma descentralizada. A instalação de pólos de apoio, verdadeiros centro de estudo para atendimento presencial aos alunos é indispensável para um sistema de ensino-aprendizagem de qualidade. A montagem de bibliotecas, videotecas, cdtecas, salas com computadores com acesso a internet e vídeo-conferência e laboratórios de física, química e biologia são infra-estruturas de apoio que podem contribuir significativamente para a oferta de qualidade da educação superior na modalidade a distância. Como esses recursos são caros e precisam ser periodicamente atualizados não basta só disponibilizar os recursos, mas estruturar uma forma de oferecer manutenção e atualização dos equipamentos.

Esses recursos podem vir de parcerias entre prefeituras, governo estadual e empresas públicas ou privadas interessadas no desenvolvimento da região. $\mathrm{O}$ trabalho de articulação extrapola as fronteiras da universidade. Linhas de financiamento na Finep, BNDES e outras podem ser acionadas para viabilizar a alocação desses recursos em locais onde de outra forma não seriam alocados.

e) Implementação de serviços de comunicação, adequados e subsidiados, para a EAD em todo o território nacional 
Depois da privatização das telecomunicações no país passamos a ter mais oferta de serviços, porém a custos mais elevados. Como a educação é uma área da maior relevância para o desenvolvimento, sugere-se é que tais tarifas para fins educacionais sejam reduzidas consideravelmente, dado ao interesse público envolvido nessa atividade. Um amplo acordo entre operadoras, universidades e governo seria fundamental para institucionalização da EAD com o crescimento da oferta de cursos em todo o país em função do barateamento das tarifas de telecomunicações. Portanto, sugere-se uma interlocução do Ministério da Educação com o Ministério das Telecomunicações para a solução do problema.

f) Criação de mecanismos para viabilizar uso compartilhado de material didático elaborado pelas Instituições Públicas

As regras de uso compartilhado do material didático produzido para o curso devem ser estabelecidas com maior clareza. Os materiais produzidos para uma Universidade ou para um programa devem pertencer à Instituição financiadora, à Universidade que o produziu ou a ambos? A remuneração de autores de material didático encontram-se definidas em contrato de acordo com o Direito Autoral? A sugestão é que os materiais utilizados para cursos públicos e gratuitos não sejam cobrados e nem os autores remunerados. Caso o material didático seja comercializado de algum modo é que caberia uma remuneração ao autor a título de compromisso moral da instituição. Esse tema precisa ser melhor estudado e aprofundado para que o Ministério da Educação possa de algum modo democratizar as experiências entre as instituições públicas de ensino superior. Essa medida resultaria em uma economia de tempo e de dinheiro público e poderia acelerar o processo de institucionalização da EAD no país.

\section{Considerações Finais}

Uma política de EAD responsável, consistente e institucionalizada no espaço da universidade pública é fundamental para expansão da oferta de vagas no ensino superior de qualidade no país. As IPES interessadas em fomentar a EAD no Brasil devem estar atentas para os desdobramentos dessa política que exige competência gerencial e técnica além da competência cognitiva demonstrada pelas universidades brasileiras. Essa política pode apontar o caminho para a introdução definitiva da virtualidade e as novas TIC no Ensino Superior Público. Com esses avanços estaremos indo além das distâncias geográficas, promovendo desenvolvimento humano, criando consciência cidadã e ampliando oportunidades de crescimento para os locais mais isolados e distantes do país. Integrando um país continental não somente pela língua e pela cultura, mas também por seus saberes em diferentes áreas de conhecimento oferecidos a todos os brasileiros. Com o Ensino Superior a Distância faremos da interação e da interatividade uma realidade para aproximar as universidades dos cidadãos e ampliar as oportunidades profissionais. Com a institucionalização da EAD, as IPES estarão aproximando-se da sociedade de uma forma muito mais efetiva, consolidando seu papel social de forma inexorável. Essa visão positiva da EAD não se constrói somente com o exercício de uma vontade política. A implantação de cursos

de EAD requer recursos especiais, profissionais competentes e e uma metodologia de ensino diferenciada. O objetivo desse artigo foi iniciar esse debate. É preciso pensar nos detalhes para construção de sistemas de educação a distância que proporcionem um ensino de qualidade e isso não é fácil de se conseguir sem um grande trabalho e um investimento considerável. Gostaríamos de ampliar essa discussão e dos temas aqui levantados para que possamos enriquecer e melhorar essa política em todos os seus sentidos. 


\section{Referências}

ALONSO, K M. A educação a Distância e um Programa Institucional de Formação de Professores em Exercício In: PRETI, O. (Org.). Educação a distância: construindo significados. Cuiabá: Nead/IE-UFMT; Brasília: Plano, 2000. p. 229-246.

MORAN, J. M. Pedagogia integradora do presencial-virtual. Disponível em: <http://www.eca.usp.br/prof/moran/ pedagogia.htm>. Acesso em: 5 nov. 2003.

ORGANIZAÇÃO DAS NAÇÕES UNIDAS PARA A EDUCAÇÃO, A CIÊNCIA E A CULTURA. Conferência Mundial sobre o Ensino Superior. Tendências de educação superior para o século XXI. Brasília: Unesco: Conselho de Reitores das Universidades Brasileiras, 1999. p. 665-669. Anais da Conferência mundial convocada pela Unesco em 1998.

PROPOSTA da Andes para a universidade brasileira. Cadernos Andes, Florianópolis: Andes, n. 2,1981 .

SCHWARTZMANN, J. A administração de universidades públicas: a racionalidade da ineficiência. Educação Brasileira, Brasília. In: SOARES, MSA (Org). O financiamento do ensino superior no Brasil na década de 90. Brasília: Coordenação de Aperfeiçoamento de Pessoal de Nível Superior, 2002. v.15, n. 31 p. 59-106.

\section{ANEXO 1 \\ DOCUMENTO PRÓ-LICENCIATURA FASE I}

Brasília 28 de abril de 2005

Reunião de Trabalho do Pró-Licenciatura Fase I/SEED/MEC

Os participantes da reunião de trabalho do Pró-Licenciatura fase 01 , realizado no período de 26 a 28 de abril de 2005 em Brasília, destacam a importância da implementação de programas de Educação Superior a Distância no Brasil e, da mesma forma, congratulam as secretarias SEESP/SESu/SEB/SEED-MEC pela iniciativa de diálogo na busca de parceria inédita no País. Entretanto, salientam que importantes ações devam ser consolidadas, de maneira que se implementem sistemas permanentes de Educação a Distância-EAD, com objetivo de atender com qualidade o público que deles fará uso. Nesse sentido, são necessárias medidas urgentes para:

a. abertura de novas vagas para docentes e técnicos administrativos, que atendam a demanda dos programas de educação à distância;

b. viabilização institucional da remuneração de profissionais envolvidos no sistema de EAD; 
c. inclusão dos alunos da Educação a Distância nas matrizes orçamentárias das IES públicas, para assegurar o custeio do sistema de EAD;

d. destinação de recursos financeiros para implantar e implementar a infra-estrutura do sistema de EAD;

e. implementação de serviços de comunicação, adequados e subsidiados, para a EAD em todo o território nacional;

f. criação de mecanismos para viabilizar uso compartilhado de material didático elaborado pelas Instituições Públicas.

Os participantes da reunião de trabalho do Pró-Licenciatura Fase I entendem que, com a efetivação das medidas acima relacionadas, dar-se-á a capilarização do sistema de Educação em nosso país, promovendo a inclusão social. Entendem, também, que o acesso ao ensino superior público, gratuito e de qualidade, é condição básica para democratização das oportunidades sociais da população brasileira.

Representantes dos Consórcios da UNIREDE que compõem o Pró-Licenciatura Fase I:

Consórcio Setentrional, Consórcio Pró-Formar, CampusNET Amazônia, Consórcio Nordeste Oriental, Consórcio EAD-PR-Noroeste, EAD-PR-Centro, Consórcio RediSul, Consórcio CEDERJ, Consórcio Rural-UESB.

\begin{tabular}{|c|c|c|c|c|c|c|}
\hline \multicolumn{7}{|c|}{ Repasse de Capital e Custeio - Chamada Pública 001/200 Seed Mec } \\
\hline \multicolumn{6}{|c|}{ 1음 Luar } & \\
\hline \multirow[b]{2}{*}{ Licenciatura } & \multirow[b]{2}{*}{$\begin{array}{l}\text { Nome do } \\
\text { Consórcio }\end{array}$} & \multirow[b]{2}{*}{ IES Envolvidas } & \multirow[b]{2}{*}{ UF } & \multicolumn{3}{|c|}{$3.000 .000,00$} \\
\hline & & & & No. Vag & $\begin{array}{l}\text { Repasse } \\
\text { Capital }\end{array}$ & $\begin{array}{l}\text { Repasse } \\
\text { Custeio }\end{array}$ \\
\hline \multirow[t]{3}{*}{ Física } & CEDERJ & Univ. Federal do Rio de Janeiro & RJ & 530 & $115.106,00$ & $280.829,00$ \\
\hline & & Univ. Federal Fluminense & RJ & & & \\
\hline & & Univ. do Estado do Rio de Janeiro & RJ & & & \\
\hline \multirow[t]{5}{*}{ Biologia } & $\begin{array}{l}\text { Consórcio } \\
\text { Setentrional }\end{array}$ & Universidade de Brasília Unb & DF & 1325 & $413.795,00$ & $1.340 .652,00$ \\
\hline & & Univ. Federal de Goiás - UFG & GO & & & \\
\hline & & Univ. Estadual de Goiás- UEG & GO & & & \\
\hline & & $\begin{array}{l}\text { Univ. Fed. de Mato Grosso do Sul - } \\
\text { UFMS }\end{array}$ & MS & & & \\
\hline & & $\begin{array}{l}\text { Univ. Est. De Mato Grosso do Sul - } \\
\text { UEMS }\end{array}$ & MS & & & \\
\hline
\end{tabular}




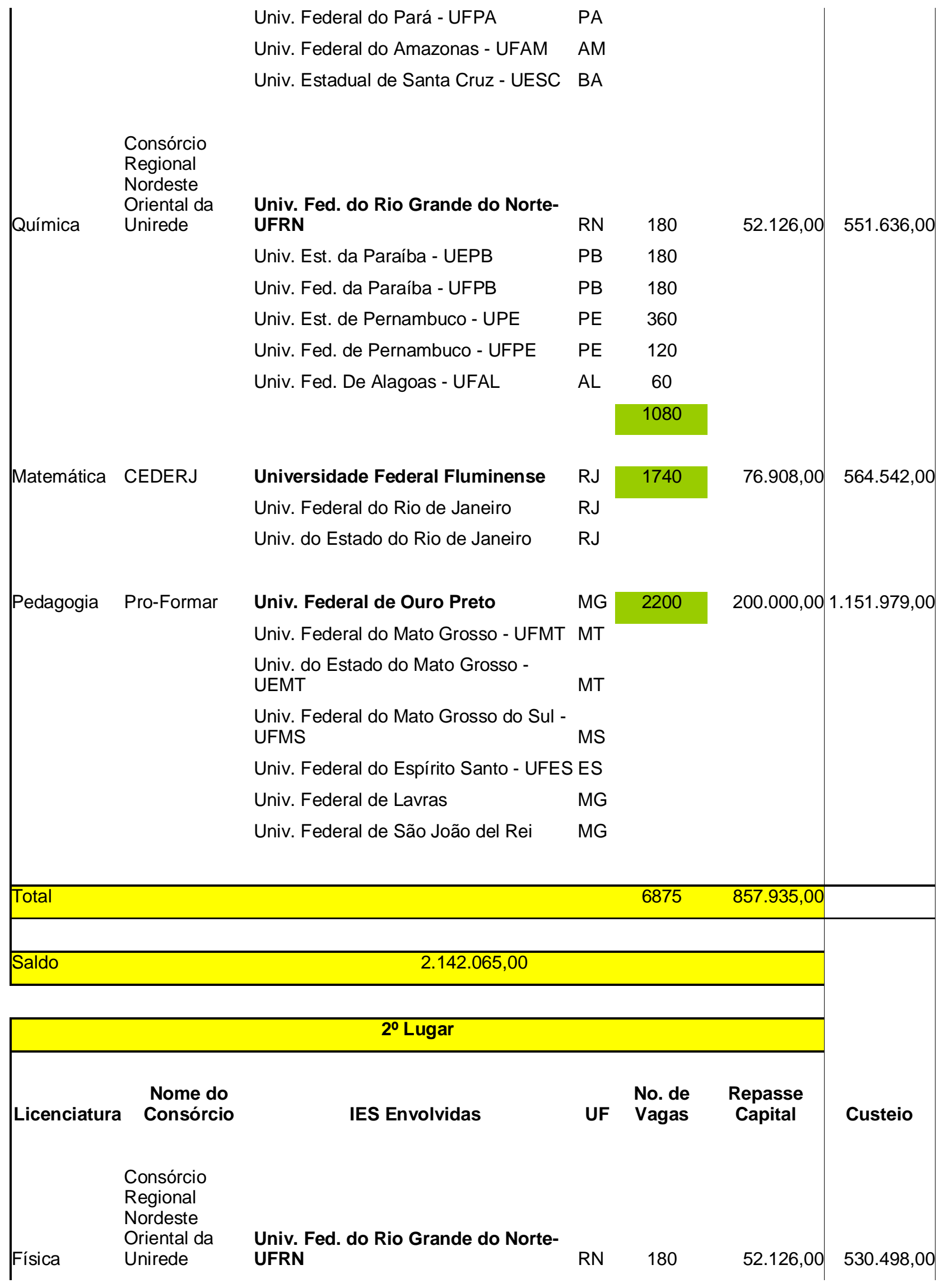




\begin{tabular}{|c|c|c|c|c|c|c|}
\hline & & Univ. Est. da Paraíba - UFPB & PB & 180 & & \\
\hline & & Univ. Fed. da Paraíba - UFPB & PB & 180 & & \\
\hline & & Univ. Est. de Pernambuco - UPE & PE & 360 & & \\
\hline & & Univ. Fed. de Pernanbuco - UFPE & PE & 60 & & \\
\hline & & Univ. Fed. De Alagoas - UFAL & $\mathrm{AL}$ & 60 & & \\
\hline & & & & 1020 & & \\
\hline Biologia & Cederj & Univ. Est. do Norte Fluminense & RJ & 1195 & $256.361,00$ & $371.728,00$ \\
\hline & & Universidade Federal Fluminense & RJ & & & \\
\hline & & Univ. Federal do Rio de Janeiro & RJ & & & \\
\hline & & Univ. do Estado do Rio de Janeiro & RJ & & & \\
\hline Química & $\begin{array}{l}\text { CampusNet } \\
\text { Amazônia }\end{array}$ & Universidade Federal do Pará & PA & 300 & $345.272,56$ & $627.920,00$ \\
\hline & & Universidade do Estado do Pará & PA & 300 & & \\
\hline & & & & 600 & & \\
\hline Matemática & $\begin{array}{l}\text { Consórcio } \\
\text { Regional } \\
\text { Nordeste } \\
\text { Oriental da } \\
\text { Unirede }\end{array}$ & $\begin{array}{l}\text { Univ. Fed. do Rio Grande do Norte- } \\
\text { UFRN }\end{array}$ & $\mathrm{RN}$ & 180 & $52.126,00$ & $551.636,00$ \\
\hline & & Univ. Est. da Paraíba - UEPB & PB & 180 & & \\
\hline & & Univ. Fed. da Paraíba - UFPB & PB & 180 & & \\
\hline & & Univ. Est. de Pernambuco - UPE & PE & 360 & & \\
\hline & & Univ. Fed. de Pernanbuco - UFPE & PE & 120 & & \\
\hline & & Univ. Fed. de Alagoas - UFAL & AL & 60 & & \\
\hline & & & & 1080 & & \\
\hline Pedagogia & REDiSUL & Universidade Federal de Santa Maria & RS & 480 & $200.000,00$ & $572.070,00$ \\
\hline & & $\begin{array}{l}\text { Universidade Federal de Santa } \\
\text { Catarina }\end{array}$ & sc & & & \\
\hline & & $\begin{array}{l}\text { Universidade Federal do Rio Grande do } \\
\text { Sul }\end{array}$ & RS & & & \\
\hline & & Universidade Estadual de Maringá & PR & & & \\
\hline Total & & & & 4375 & & \\
\hline Saldo & & $1.236 .179,44$ & & & & \\
\hline & & 3ㄴ Lugar & & & & \\
\hline
\end{tabular}




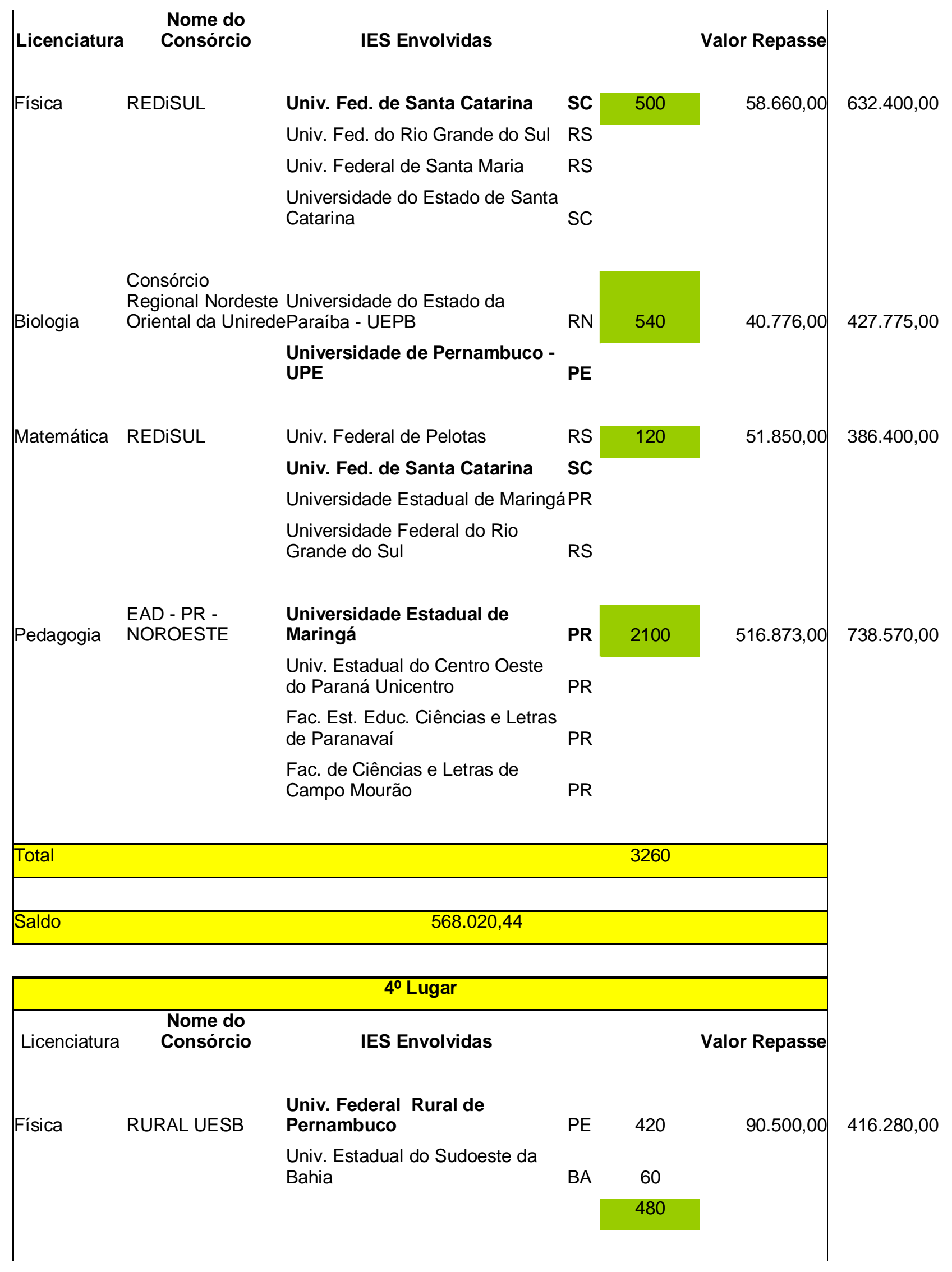




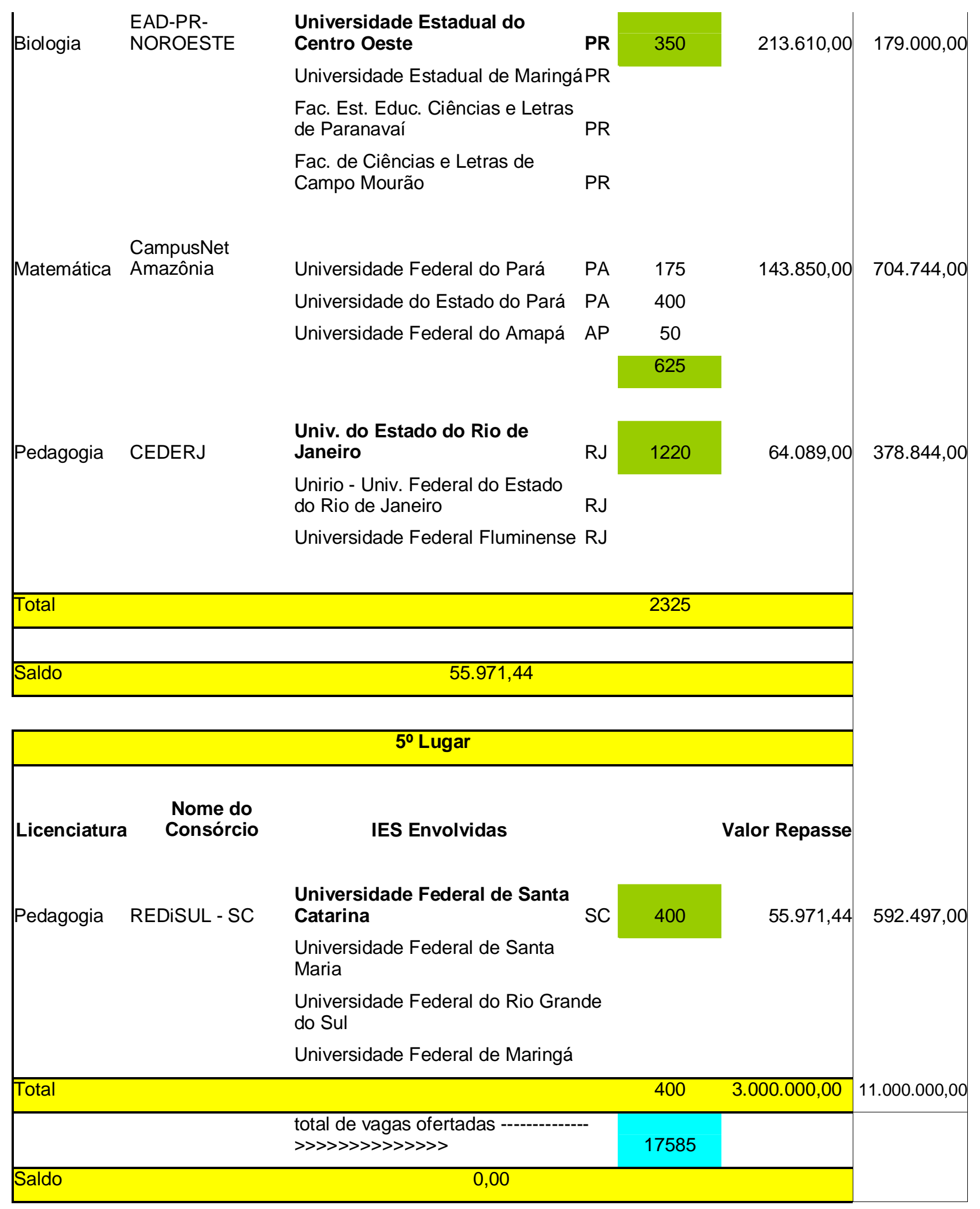


A pontuação de um Projeto de Curso será calculada pela fórmula abaixo:

PT $=4 \times($ Pgeo + Pof + Peqm $)+5 \times$ Pprj $+3 \times$ Pea, onde:

PT $=$ pontuação final obtida pelo Projeto de Curso;

Pgeo = pontos atribuídos a "Abrangência Geopolítica";

Pof = pontos atribuídos a "Oferta";

Peqm = pontos atribuídos a "Equipe Multidisciplinar";

Pprj = pontos atribuídos a "Projeto Pedagógico";

Peadm = pontos atribuídos a "Estrutura Administrativa". 